\title{
Review on Important Extrinsic Determinants on Turnover Intention
}

\author{
Yong B. Shin \\ Community Service and Continuing Education Deanship \\ Management Department \\ E-mail: YShin@fmarion.edu
}

\begin{abstract}
This study identifies possible extrinsic sources that generate dissonance and finds important decision variables that may improve information systems (IS) professionals' level of satisfaction. A logit model presents four important factors that produced significant impacts on the formulation of turnover intention: the level of satisfaction, the level of fitness, amount of managerial input (freedom, job variety), and amount of nonmonetary output (career progress opportunities, chance to learn).Both job satisfaction and level of fitness are considered as intermediate variables that link input variables to turnover intention.
\end{abstract}

Keywords: extrinsic variables, trade-off alternatives, turnover intention

\section{Introduction}

The training of new IS professionals requires considerable time and is highly influenced by rapid changes in technologies. IS professional's turnover may result in considerable costs to recruit, select, and train new employees before they become productive. The lack of clarity regarding the reasons for turnover and the inaccuracy of organizational data for turnover reasons encourage the use of turnover intention. Fishbein and Ajzen (1975) contended that "the best single predictor of an individual's behavior be a measure of his intention to perform that behavior."

The analysis of turnover intention can handle other aspects of turnover as well. The analysis of turnover intention can exclude those who leave for organizationally unavoidable reasons such as moving to another spouse-imposed location or medical problems. By excluding these factors, the analysis can isolate the pertinent variance in turnover that can be controlled by management. The analysis of turnover intention can also include the perceptions of those employees who try to leave the organization sooner or later. By including them, the analysis of turnover intention can provide valuable information on how to keep qualified IS professionals.

Turnover intention takes place when employees try to revise their previous choices relating to their current job. It is assumed that their previous choices were their best alternatives available when the decisions were made. Therefore, it is vitally important to understand why IS professionals revised the previous choices. The process of equilibrium (Piaget, 1980) provides a way to explain how IS professionals arrived at turnover intention. The differences between actual job features and these standards generate 'disequilibrium' which calls for amendment. Employees may have different standards of comparison and different preferences toward job features. Therefore, individual differences in the formation of 'disequilibrium' that results in turnover intention should also be considered (Salancik\& Pfeffer, 1979).

Individual differences may be reflected in the way in which employees evaluate possible alternatives. When evaluating possible alternatives, an employee tries to maximize his/her utility value. Employees prefer the alternative with the largest amount of outputs for a given amount of inputs, or the alternative with the smallest amount of inputs for a given amount of outputs. Trade-offs may exist between decision. If trade-offs exist, the effect of one variable on turnover intention cannot be evaluated alone.

\section{Variables Related to a Job}

Because turnover intention is formulated while an employee is working on the current job, the analysis of job characteristics is important to understand turnover. The static approach has been used to focus on the analysis of constituent elements of a job, such as work itself, supervision, promotion opportunity, pay, and coworkers (Smith, Kendall and Hulin, 1969); skill variety, task identity, task significance, autonomy, and task feedback (Hackman and Oldham, 1976).

However, the dynamic approach emphasizes the process by which job characteristics influence turnover intention and job attitudes. Attractiveness is a utility function of perceived outputs. The possibility of attaining outcomes can be replaced with the amount of input to get the outcomes. Therefore, choices about a job are based on the interaction between input and output job characteristics. Thus, general system theory is useful to consider the interaction. To apply the system theory, decision variables are divided into two categories: input and output. Table 1 presents important job characteristics which are classified based on the system theory. Input characteristics are 
divided into two subcategories: amount and difficulty and managerial style. Output characteristics are divided into two subcategories: monetary and non-monetary rewards.

\begin{tabular}{|l|l|l|}
\hline \multirow{4}{*}{ Input } & Amount \& Difficulty & $\begin{array}{l}\text { Work Load } \\
\text { Difficult } \\
\text { Job Stress }\end{array}$ \\
\cline { 2 - 3 } & Managerial Style & $\begin{array}{l}\text { Job variety } \\
\text { Freedom } \\
\text { Working conditions }\end{array}$ \\
\hline \multirow{3}{*}{ Output } & Modetary & $\begin{array}{l}\text { Current pay level } \\
\text { Benefits } \\
\text { Incentive }\end{array}$ \\
\cline { 2 - 3 } & Non-monetary & $\begin{array}{l}\text { Career progress opportunities } \\
\text { Job security } \\
\text { Chance to learn }\end{array}$ \\
\hline
\end{tabular}

Sources: Mobley et al. (1979), Locke (1976), and Hom and Griffeth(1991)

Table 1. Four Categories of Decision Variables

This study focuses on the importance of trade-off alternative choices among decision variables. The following three trade-offs are possible; (a) trade-off between input and output variables, (b) trade-off among input variables, and (3) trade-off among output variables. A rational employee must select one of the following alternatives: (a) alternatives which offer the highest outputs for a given amount of inputs, and (b) alternatives which require the lowest amount of inputs for a given level of outputs.

\section{Research Hypotheses}

The framework of this study is composed of the overall level of fitness, satisfaction, and two discrepancy sources in which the decision variables are interrelated (Figure 1).

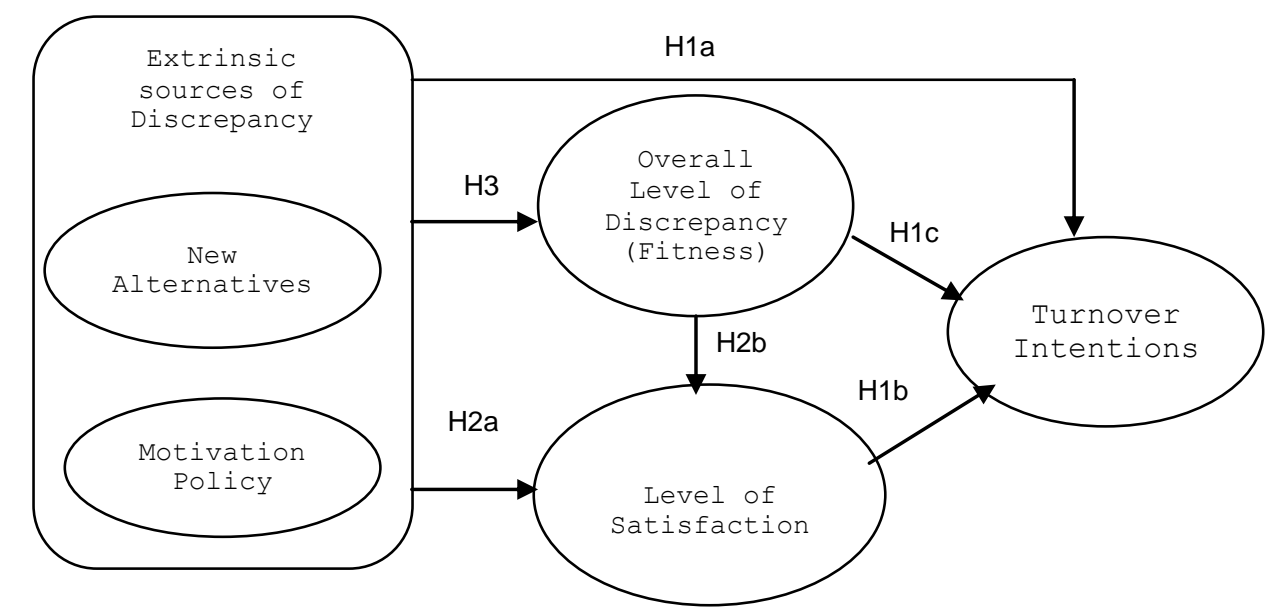

Figure 1. Research Framework and Hypotheses

This study uses turnover intention as a target variable as a final product of the cognitive process that tries to remove the dissonance. The research model is designed to find extrinsic variables that create the dissonance in the formulation of turnover intention.

H1a: IS professionals whose level of discrepancies is high display a higher chance of generating turnover intention.

H1b: IS professionals whose level of fitness to the current job is low display a higher chance of generating turnover intention.

H1c: IS professionals who are dissatisfied with the current job display a higher chance of generating turnover intention.

The first set of hypotheses concerns the role of the following variables in formulating turnover intention among IS professionals: 1) levels of discrepancies resulting from two different extrinsic sources, 2) the level of fitness, and 3) the level of satisfaction. The purpose of these hypotheses tests is to find important reasons that generate turnover intention. 
The first possible extrinsic source of discrepancy is 'the perception of available alternatives. 'Many previous studies (Hulin et al. 1985; Bluedorn, 1982; Mobley et al., 1979) examined the impact of perceived alternatives on turnover intention and reported that perceived alternatives were indirectly related to turnover intention. Employees who have abundant and attractive job opportunities outside the organization will experience less satisfaction.

Marketable employees request that they be compensated at the same level as others in the market.The "greener grass" phenomenon (Schneider, 1976) holds that "the more abundant and attractive jobs are available outside of the organization, the less satisfaction employees will experience in their current position."

Another extrinsic source of discrepancy in this study is 'the appropriate use of motivation policy' to match employees' needs with rewards. Employees are motivated when their needs are met through the motivation policies used by an organization.If motivators emphasized by the organization are different from those preferred by employees, discrepancy may be created for the employee.The inappropriate application of motivation policies can be another source of discrepancy.Wanous (1980) and Vandenberg \& Scarpello (1990) applied the need-reward matching concept to explain voluntary turnover and suggested that the level of mismatch of reward policies with employees' needs is directly related to voluntary turnover.

The appropriateness of motivational policies is not based on static job characteristics, but dynamic job characteristics. Dynamic job characteristics imply trade-off (interaction) among conflicting job characteristics. Trade-offs themselves also reflect the needs of an employee. Therefore, the appropriateness of motivational policies can measure the level of need-reward match.

The role of the level of satisfaction in generating turnover intention is also examined by some previous studies (Baroudi, 1985; Cotton and Tuttle, 1986).The studies indicated a negative relationship between job satisfaction and turnover intention. However, a low amount of variance is explained in both studies.

H2a: The levels of discrepancies are significantly related to the level of satisfaction.

$\mathrm{H} 2 \mathrm{~b}$ : The level of fitness to the current job is significantly related to the level of satisfaction.

The second set of hypotheses concerns the role of the following variables in determining the level of satisfaction: 1) levels of discrepancies resulting from different sources and 2) the level of fitness. These hypotheses tests assume that job satisfaction plays an important role in generating turnover intention. If the determinants of job satisfaction are different from those of turnover intention, job satisfaction can be considered as an intermediate variable which connects its determinants with turnover intention. Rice et al. (1990) examined the association of multiple discrepancies with the satisfaction level. Their results indicate that the hypothesis related to the strong association is generally well supported.

H3: The levels of discrepancies are significantly related to the level of fitness.

Hypothesis 3 concerns the association of the levels of discrepancies resulting from different sources with the level of fitness. Hypothesis 3is developed on the fact that IS professionals who think they do not fit their current jobs can be vulnerable to dissatisfaction and/or turnover intention. Therefore, it may be important to identify the determinants of the level of fitness.

\section{Data analysis}

The research instrument consisted of three parts. The first part contained 12 items to collect data on the level of organizational stagnation, job satisfaction, desire to quit, intent to quit, and other measures to validate the overall level of discrepancy. The second part is designed to measure the level of discrepancy resulting from the gaps between individual needs and organizational rewards.

IS professionals are asked to choose between two conflicting job characteristics, and to indicate the level of preference for the choice. An IS professional's preference reflects his/her needs, while the organization preference reflects the organization's motivation policies. The differences between the two are used as the level of discrepancy for this source.

The third part captures data to examine the level of discrepancy regarding perceived alternatives in other organizations by examining the attractiveness of the alternatives. IS professionals are asked to compare the present job to the alternatives in other organizations with respect to the 11 job features (except Incentives) (Table 1). A total 25 responses (24.0\%) is collected from the 103 questionnaires, and a usable return rate is 20.3 percent (21 usable questionnaires). The important decision variables (job features) used to represent the two extrinsic sources of discrepancy are abbreviated throughout this study as shown in Table 2. 
Source 1: Attractiveness of Alternatives

C_PAY -The level of attractiveness toward the alternatives in other organizations in terms of pay level.

C_BNFT -The level of attractiveness toward the alternatives in other organizations in terms of benefits and incentives.

C_CAREER -The level of attractiveness toward the alternatives in other organizations in terms of career progress opportunities.

C_CHANCE -The level of attractiveness toward the alternatives in other organizations in terms of chance to learn.

C_SECURE -The level of attractiveness toward the alternatives in other organizations in terms of job security.

C_LOAD -The level of attractiveness toward the alternatives in other organizations in terms of work load.

C_COND -The level of attractiveness toward the alternatives in other organizations in terms of working conditions.

C_STRESS -The level of attractiveness toward the alternatives in other organizations in terms of job stress.

C_FREE -The level of attractiveness toward the alternatives in other organizations in terms of the amount of freedom to do the job.

C_VARY -The level of attractiveness toward the alternatives in other organizations in terms of job variety.

C_COWORK -The level of attractiveness toward the alternatives in other organizations in terms of coworkers.

Source 2: Appropriateness of Motivation Policies

I_WORK -The difference between IS_WORK and Org_WORK.

I_STRES -The difference between IS_STRES and Org_STRES.

I_RISK -The difference between IS_RISK and Org_RISK.

I_FREE -The difference between IS_FREE and Org_FREE.

I_AMBIG -The difference between IS_AMBIG and Org_AMBIG.

I_ROUT -The difference between IS_ROUT and Org_ROUT.

I_LEARN -The difference between IS_LEARN and Org_LEARN.

I_CAREE -The difference between IS_CAREE and Org_CAREE.

I_ESTM -The difference between IS_ESTM and Org_ESTM.

I_COWOR -The difference between IS_COWOR and Org_COWOR.

Table 2. Abbreviations for Decision Variables

First, descriptive statistics (mean and standard deviation) for the appropriateness of motivation policies are presented in Table 3.Each item reflects trade-off preferences (of individual and organization) between two conflicting job characteristics. For example, among input decision variables, the first variable I_WORK, represents the trade off between more work for higher pay and more leisure with less pay. The mean value of I_WORK, 3.26, is slightly lower than its middle value of 4 .Therefore, both IS professionals and organizations prefer'more work for higher pay' rather than 'more leisure with less pay.' But I_WORK shows there is no significant preference difference on 'more work vs. more leisure' between individual and organization.

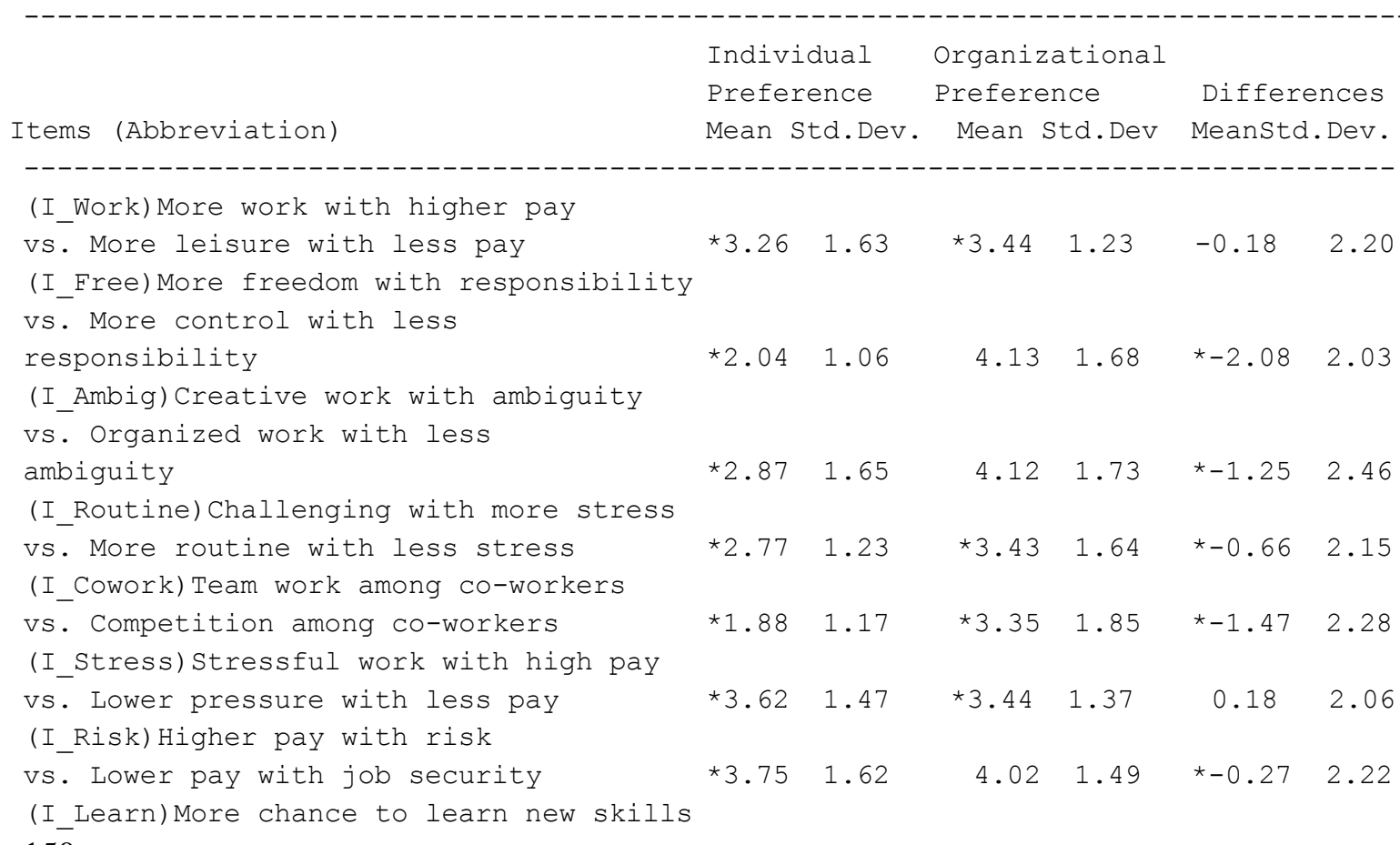




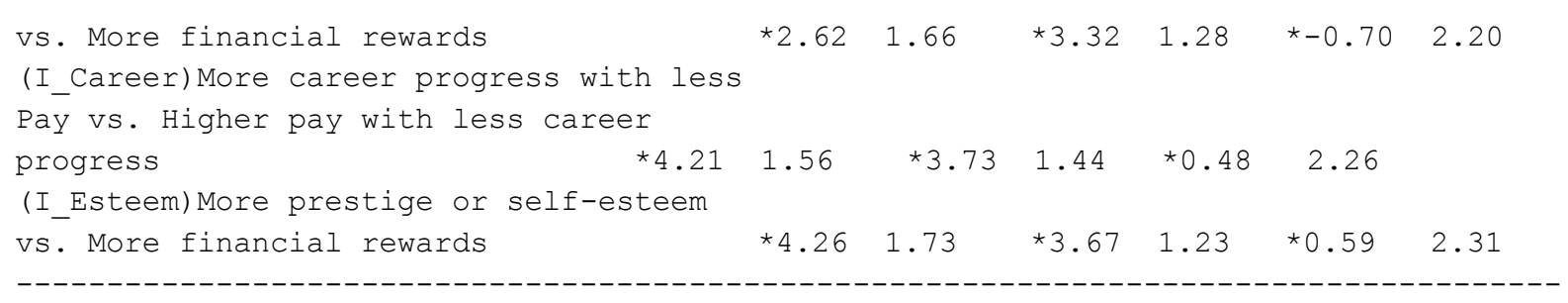

Table 3. Descriptive Statistics for the Appropriateness of Motivation Policies

The biggest gap between individual and organizational preference is 2.08 for 'more freedom with responsibility versus more control with less responsibility' denoted by I_FREE. That is, IS professionals preferred more freedom on their job, but perceived that their companies wanted to exercise more control. The second biggest gap is found in I_COWORK, the direction and level of teamwork among co-workers rather than competition among co-workers is more important to both IS professionals and organizations. 'Challenging with more stresses is also preferred by both groups rather than 'more routine with less stress.' Significant differences between IS professionals and organizations in the opposite direction are found in I_FREE and I_AMBIG decision variables. IS professionals prefer "more freedom with responsibility", but organizations prefer "more control with less responsibility." IS professionals also prefer "more creative work with ambiguity", but organizations prefer "more organized work with less ambiguity."

In output variables side, it is interesting that organizations more prefer "Stressful work with high pay" against "lower pressure with less pay", I_STRESS, than IS professionals. Both groups prefer "more chance to learn new skills" rather than "more financial rewards", I_LEARN. Other interesting points in significant preference difference in the opposite direction are with I_CAREER, I_ESTEEM, I_RISK variables. Organizations consider "more career progress with lass pay" and "more prestige or self-esteem" more important and prefer "lower pay with job security", but IS professionals prefer more "higher pay with less career progress", "more financial rewards" and "higher pay with risk."The result indicates that IS professionals consider monetary outputs more important, but as shown in I_LEARN, they prefer to have more chance to learn new skills rather than rewarded with financial values.

Second, the level of discrepancy resulting from the advent of a new alternative is measured by the attractiveness of the alternatives(Table 4). The first variable, C_PAY, indicates the level of attractiveness toward possible alternatives in terms of pay level. Mean values range from 2.83 to 3.40.The highest mean value is the value of career progress opportunities (C_CAREER) and the lowest one is the value of job security (C_SECURE).The highest mean value of C_CAREER indicates IS professionals consider that another organization can provide better career progress opportunities. The results illustrate IS professionals other organizations can provide more benefits and incentives (C_BNFT), chance to learn (C_LEARN) and better working conditions (C_COND).

\begin{tabular}{|c|c|}
\hline \multirow[t]{2}{*}{ Variables (codes) } & Comparison \\
\hline & Mean Std. Dev. \\
\hline Pay (C_PAY) & $3.13^{*}$ \\
\hline Benefits and incentives (C_BNFT) & $3.12 *$ \\
\hline Careerprogress opportunities (C_CAREER) & $3.40^{*}$ \\
\hline Chance to learn (C_LEARN) & $3.24 *$ \\
\hline (C_SECURE) & $2.83^{*}$ \\
\hline Work load (C_LOAD) & 2.970 .71 \\
\hline Working conditions (C_COND) & $3.13^{*}$ \\
\hline Job stress (C_STRESS) & 2.96 \\
\hline Amount of freedom to do my job (C_FREE) & 2.94 \\
\hline Job variety (C_VARY) & 2.96 \\
\hline Coworkers (C_COWORK) & 3.04 \\
\hline
\end{tabular}

Table 4. Descriptive statistics for Attractiveness of Alternatives in other organizations

The reliability and validity of the collected data are examined to ensure adequacy for further analysis. 12 items are used to measure the level of discrepancy, and 3 items (Q3,4 and 5) are used to assess the level of satisfaction. Cronbach's coefficient alpha for the 12 items measuring the level of discrepancy is 0.845 .Cronbach's coefficient alpha for the 3 items measuring the level of satisfaction is 0.890 . Factor analysis is used for the test of construct validity. Factor loading patterns are shown in Table 5.This study assumed the three different trade-offs among variables used by IS professionals in their turnover decision. I_WORK, I_STRES and I_RISK, which examined the effects of trade-offs between variables that decide the total amount of inputs and outputs, are loaded on factor 5.I__FREE, I__AMBIG and I__ROUT, which examined the effects of trade-offs among variables that decide the total amount of inputs, are loaded on factor 6.The three items (I_LEARN, I_CAREE, I_ESTM), which examined the effects of trade-offs among variables that decide the types of outputs, are loaded on factor 7.However, Cronbach's alpha for factor 7 is below 0.7 and there is no sound evidence for reliability. Therefore, it is excluded 
from further analysis. All other loadings related to trade-offs among decision variables are the same as expected.

\section{FACTOR1 FACTOR2 FACTOR3 FACTOR4 FACTOR5 FACTOR6 FACTOR7}

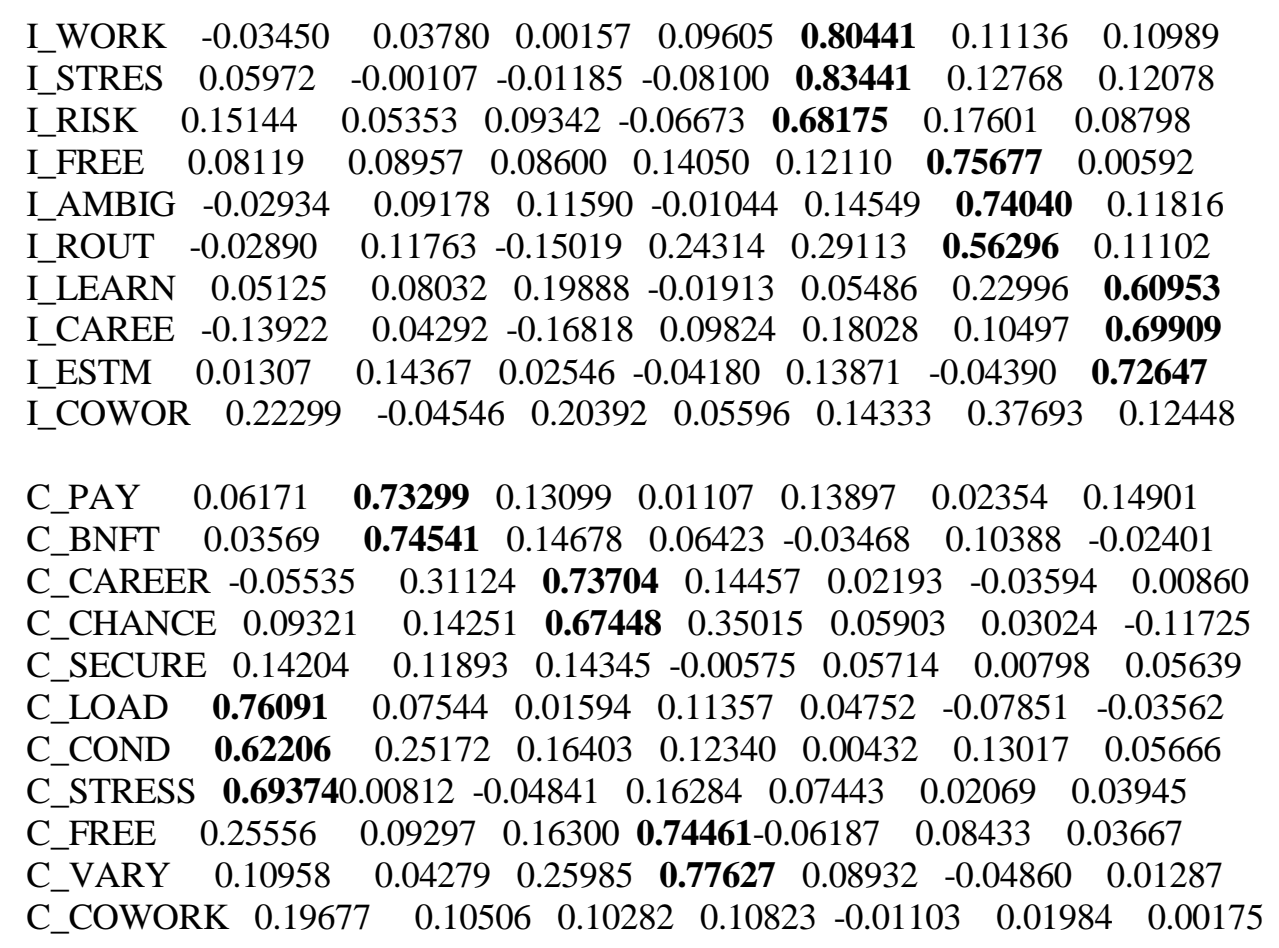

Table 5. Rotated factor pattern

The dependent variable in the MDA model, turnover intention, has two groups: IS professionals with and without turnover intention. Wilks' Lambda and Hotelling $\mathrm{T}^{2}$ test statistics are less than 0.01 . This means IS professionals with turnover intention can be different from those without turnover intention in terms of independent variables.

The level of satisfaction (S_LEVEL) had the largest F-value in Table 6.That means that the level of satisfaction makes the greatest contribution in classifying the two groups. Its $r$-square value, 0.1630 , means 16.30 percent of the total variability of the dependent variable is explained by the level of satisfaction. The level of fitness had the next largest F-value. Most of variables except factor 6 are important in the formulation of employee's turnover intention.

Each individual coefficient is tested to measure the contribution of individual variables. Chi-square and the asymptotic $t$ test results (Table 6) support the level of fitness, factor 3, factor 4 and the level of satisfaction play an important role in the formulation of turnover intention.

\begin{tabular}{|llllllll|}
\hline Variables & R-sqRSQ/(1-RSQ) & F & Pr & t-value & Pr>F \\
\hline S_level & 0.163 & 0.1947 & 80.018 & $\mathbf{0 . 0 0 0 1 8 . 2 1 3}$ & $\mathbf{0 . 0 0 0}$ & & \\
Fitness & 0.147 & 0.1726 & 70.926 & $\mathbf{0 . 0 0 0 1 3} .121$ & $\mathbf{0 . 0 0 2}$ & & \\
Factor1 & 0.014 & 0.0143 & 5.8590 .01591 .1310 .257 & & \\
Factor2 & 0.017 & 0.0168 & 6.908 & $\mathbf{0 . 0 0 8 9 1} .5330 .125$ & & \\
Factor3 & 0.093 & 0.1024 & 42.0710 .00012 .726 & $\mathbf{0 . 0 0 6}$ & & \\
Factor4 & 0.106 & 0.1185 & $48.715 \mathbf{0 . 0 0 0 1 2} 289$ & $\mathbf{0 . 0 2 2}$ & & \\
Factor5 & 0.050 & 0.0531 & 21.813 & $\mathbf{0 . 0 0 0 1 0 . 4 1 2 0 . 6 8 2}$ & & \\
Factor60.008 & 0.0075 & 3.0890 .0796 & 0.300 & 0.768 & & \\
\hline
\end{tabular}

Table 6. Univariate Statistics for the Significance Test of Discriminant Function

Regression analysis identifies the following variables as the determinants of the level of satisfaction: amount of non-monetary output (factor3), managerial characteristics of input (factor5), and the level of fitness (Table 7). In Table 7, regression analysis to examine the relationship between important factors identified and the level of fitness identifies managerial input variables (Factor 4, freedom and variety) as the determinant of the level of fitness. However, R-square is 0.12. It implies that the level of fitness is not explained well by the variables included in the model. 


\section{Conclusion}

This study has attempted to provide useful information to help management retain IS professionals by considering two aspects of turnover intention: 1) human information processing and 2) the trade-off among decision variables. The use of human information processing is an attempt to find possible sources that generate discrepancy which can lead to turnover intention. Consequently, the study examined how IS professionals evaluated possible alternatives. It is assumed that IS professionals try to maximize their utility value through trade-offs among decision variables.

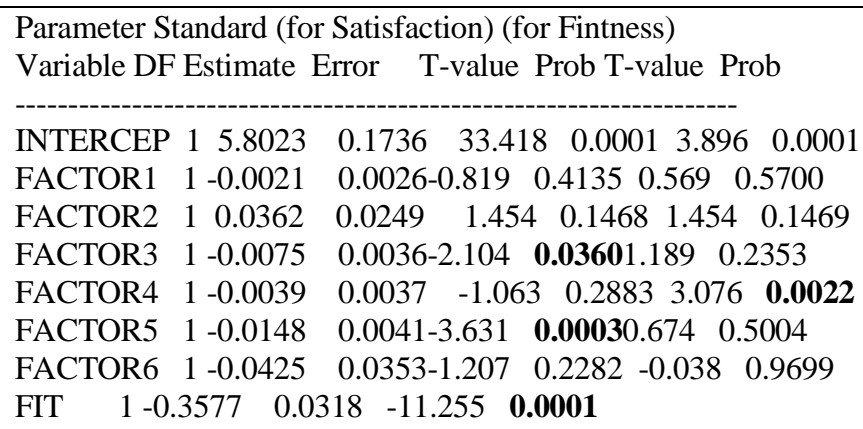

Table 7. The Results of Regression Analysis for the Level of Satisfaction and Fitness

This study identifies the following four important factors that produced significant impacts on the formulation of turnover intention: the level of satisfaction, the level of fitness, amount of non-monetary output (factor3), and amount of managerial input (factor4). The level of fitness and the level of satisfaction also play an important role in the formulation of turnover intention. Therefore, it is appropriate to examine antecedents of the two variables. The following three factors are found from regression analysis as the determinants of the level of satisfaction: the level of fitness, non-monetary output (factor3), and trade-offs between input and output variables (factor5). This finding indicates that variables related to the input side such as work load and job stress exert an influence on the formulation of turnover intention through the level of satisfaction.

According to Baroudi's study (1985), the association of input variables with turnover intention is not strong, even though it is significant. However, a strong association of those input variables with the level of satisfaction is reported. This means that the input variables are important antecedents of job satisfaction, but they are not important determinants of turnover intention. Therefore, job satisfaction can be considered as an intermediate variable which links input variables and turnover intention.

Another regression analysis identifies trade-offs between input and output variables (factor5) as the determinant of the level of fitness. IS professionals might consider quitting the jobs to resolve the state of discrepancy, when they feel not fitting their current jobs. Aronoff and Ward (1990) found the importance of the current level of organizational stagnation. The more overloaded an organization is with mature superiors, the lower opportunities to be promoted. And the lower opportunities to be promoted, the lower the opportunities to meet employees' growth needs. Lower opportunities to meet growth needs may result in a greater discrepancy. The current level of organizational stagnation directly impacts on the level of fitness and the level of satisfaction.

\section{References}

Aronoff, C. E. \& War, J. L. (1990). Employee Turnover Has its Good Side. Nation's Business. April: 53-55.

Baroudi, J. J.(1985). The Impact of Role Variables on IS Personnel Work Attitudes and Intentions. MIS Quarterly. 9.4: 341-356.

Bluedorn, Allen. (1982).A Unified Model of Turnover from Organizations. Human Relations. 35.2: 135-153.

Cotton, J. L. \&Tuttle, J. M. (1986) Employee Turnover: A Meta-Analysis and Review with Implications for Research. Academy of Management Review. 11.1: 55-70.

Fishbein, M. \& Ajzen, I. (1975). A Meta-Analysis of the Correlates of Role Conflict and Ambiguity.

Journal of Applied Psychology. 68.3: 320-333.

Hackman, J. R. \& Oldham, G. R. (1975). Development of the Job Diagnostic Survey.Journal of Applied Psychology. 60: 159-170.

Hulin, C. L.\&Roznowski,M.\&Hachiy, D. (1985). Alternative Opportunities and Withdrawal Decisions: Empirical and Theoretical Discrepancies and Integration.Psychological Bulletin. 97: 233-250. 
Mobley, W. H.\&Griffeth,R. W. \& Hand,H. H. \&Meglino, B. M. (1979)."Review and Conceptual Analysis of the Employee Turnover Process." Psychological Bulletin. 86.3:493-522.

Piaget, Jean. (1980).Adaptation and Intelligence: Organic Selection and Phenocopy.Chicago :University of Chicago Press.

Rice, R.W.\&Phillips, S.M. \&McFarlin, D.B. (1990). Multiple Discrepancies and Pay Satisfaction. Journal of Applied Psychology. 75(4):386-393.

Salancik, G. R.\&Pfeffer, J.(1978). A Social Information Processing Approach to Job Attitude and Task Design. Administrative Science Quarterly. 23.3: 224-253.

Schneider, J. (1976). The Greener Grass Phenomenon: Differential Effects of a work Context Alternative on Organizational Participation and Withdrawal Intentions.Organizational Behavior and Human Performance. 16(2):308-333.

Smith, P. C.\& Kendall, C.\& Hullin, C. (1969). The Measurement of Satisfaction in Work And Retirement. Chicago: Rand McNally.

Vandenberg, R. \&Scarpello, V. (1990). The Matching Model: An Examination of the Processes Underlying Realistic Job Previews. Journal of Applied Psychology. 75.1: 6067.

Wanous, J. P. (1980). Organizational Entry: Recruitment, Selection, and Socialization of Newcomers. Reading, MA: Addison-Wesley. 